\title{
Structural and Functional Properties of Reticulospinal Neurons in the Early-Swimming Stage Xenopus Embryo
}

\author{
P. van Mier ${ }^{1,2}$ and H. J. ten Donkelaar ${ }^{1}$ \\ 'Department of Anatomy and Embryology, University of Nijmegen, Nijmegen, The Netherlands, and 'Department of \\ Zoology, University of Bristol, Bristol, England
}

This study presents direct evidence that in Xenopus laevis embryos ipsi- and contralaterally descending reticulospinal fibers from the caudal brain stem project to the spinal cord, where they directly contact primary motoneurons. At stage 30 , occasional contacts between primary motoneurons and descending axons are present. These contacts are possibly already functional since presynaptic vesicles were sometimes observed. Furthermore, the physiological data obtained in this study suggest that reticulospinal neurons in the caudal brain stem are involved in the central generation of early swimming.

The first ingrowth of reticulospinal axons was observed in the rostral spinal cord after application of HRP to the caudal brain stem of stage $27 / 28$ embryos. By stage 32, many supraspinal axons could be found in the spinal cord at the level of the 12/13th myotome, near the time of the first rhythmic swimming. Both lamellipodial and varicose growth cones were found. Intracellular recordings from the brain stem and extracellular recordings from the myotomal muscles in curarized embryos around stage 30 revealed neurons in the caudal brain stem which were active during early fictive swimming. After intracellular staining with Lucifer yellow neurons with descending axons were found in the brain-stem reticular formation. These reticulospinal neurons showed "motoneuron-like" phasic activity, producing one spike each swimming cycle. Rhythmically occurring spikes with swimming periodicity were superimposed on a sustained depolarization level of some 5-30 mV.

Reticulospinal neurons in the brain stem resemble descending interneurons in the spinal cord by their morphology, projection pattern, and activity during early swimming. Reticulospinal neurons and descending interneurons might therefore form one continuous population of projecting interneurons with a different location but a similar function. In support of this we propose that the embryonic brain-stem reticular formation forms part of the swimming pattern generator.

\footnotetext{
Received Aug. 11, 1987; revised June 7, 1988; accepted June 20, 1988.

We thank Mrs. Linda Teagle of the Department of Zoology, University of Bristol, England, and Mrs. Doreen Elsevier, Mr. Harry van Aanholt, and Mr. Paul Posthuma for their excellent technical assistance. Dr. A. Roberts is gratefully acknowledged for helpful comments on the manuscript. This study was supported by the Foundation for Medical Research (MEDIGON) and subsidized by the Netherlands Organization for Advancement of Pure Research (N.W.O.).

Correspondence should be addressed to Dr. P. van Mier, Department of Anatomy and Neurobiology, Washington University School of Medicine, 660 South Euclid Ave., St. Louis, MO 63110.

Copyright (C) 1989 Society for Neuroscience $0270-6474 / 89 / 010025-13 \$ 02.00 / 0$
}

In the early development of locomotion in Xenopus laevis embryos roughly two phases can be distinguished (based on Coghill, 1929; Muntz, 1964; van Mier, 1986; van Mier et al., 1989): (1) the "early swimming" stage, when the first, rather irregular, movements occur which gradually develop into rhythmic bilateral alternating, undulating movements of the musculature on both sides of the body; and (2) the "free swimming" stage, when these undulations result in movement through the water. In this second phase, the spinal cord of Xenopus embryos is capable of long-lasting locomotor acts in response to brief sensory stimuli (Roberts et al., 1983).

It is now generally accepted that locomotor activity underlying locomotor behavior in vertebrates is generated within the spinal cord and to some extent in the brain stem in what has been termed central pattern (Stein, 1978; Grillner, 1981; Roberts and Roberts, 1983) or rhythm generators (Soffe, 1985). In the vertebrate CNS reticulospinal projections are among the first descending pathways to develop from the brain stem to the spinal cord (for review, see ten Donkelaar, 1982). Reticulospinal neurons in the caudal brain stem are known to contact spinal motoneurons (for example, see Shapovalov, 1972, 1975; Cruce, 1974; Babalian and Shapovalov, 1984; Babalian and Chmykhova, 1987) and might therefore participate in locomotion or pattern generation.

Within the developing spinal cord of Xenopus embryos, several types of interneurons can be distinguished on anatomical (Roberts and Clarke, 1982) and physiological grounds (Roberts et al., 1983, 1986). These interneurons, organized in longitudinal columns in the dorsolateral half of the spinal cord (Roberts and Clarke, 1982), extend into the brain-stem reticular formation (Roberts and Alford, 1986), where they closely resemble reticulospinal neurons as described in HRP studies (van Mier and ten Donkelaar, 1984; Nordlander et al., 1985; van Mier et al., 1986). The so-called commissural interneurons exert an inhibitory action during fictive swimming (Soffe et al., 1984; Dale, 1985), whereas descending interneurons play an excitatory role in central rhythm generation (Dale and Roberts, 1985; Roberts and Alford, 1986). Since the excitatory drive appeared to be a descending one (Soffe and Roberts, 1982b; Dale and Roberts, 1985), spinal interneurons and reticulospinal neurons in the brain stem (van Mier and ten Donkelaar, 1984; Nordlander et al., 1985) seem the most likely candidates for this function (Roberts and Clarke, 1982).

In this paper, which forms part of our studies of locomotor development and its neural control in $X$. laevis (for review, see van Mier, 1988), we explored the activity and morphology of reticulospinal neurons during the early tail-swimming stage. Using HRP, we investigated the early ingrowth of reticulospinal 
axons from the brain stem into the spinal cord. Simultaneous application of HRP to the caudal brain stem and the rostral myotomal muscles was used to study if and how reticulospinal axons contacted spinal motoneurons. Thick plastic sections were used for light microscopical (LM) scanning for possible contact sites. With the electron microscope (EM), these possible HRPlabeled contact sites were reexamined for the presence of chemical synapses. Finally, the activity of reticulospinal neurons was recorded during fictive swimming. Recorded reticulospinal cells were identified by intracellular marking with Lucifer yellow.

\section{Materials and Methods}

Reticulospinal neurons in the caudal brain stem were studied in X. laevis embryos, during the early and free-swimming stage (Muntz, 1964), between stages 27-40 (Nieuwkoop and Faber, 1967). The embryos were obtained by induced breeding (Pregnyl) and kept at room temperature $\left(20-22^{\circ} \mathrm{C}\right)$ in freshwater tanks.

\section{Anatomy}

Labeling of supraspinal axons. HRP (Serva) was recrystallized in very small quantities onto fine tungsten needles (tip diameter, $5-30 \mu \mathrm{m}$ ) and then applied to the caudal brain stem. For this, embryos $(n=64)$ between stages 27 and 40 were restrained under anesthesia in a dish filled with a mixture of $0.1-1.0 \mathrm{mg}$ MS $222 / 100 \mathrm{ml}$ saline (saline composition: $\mathrm{NaCl} 115 \mathrm{~mm}, \mathrm{KCl} 2.5 \mathrm{~mm}, \mathrm{CaCl}_{2} 3.0 \mathrm{~mm}, \mathrm{NaHCO}_{3} 2.4 \mathrm{~mm}, \mathrm{pH} 7.0$ 7.4). With small pins the embryos were stretched on their sides, and the exposed head skin was removed. With a fine needle the sheath covering the ventrolateral side of the brain stem was partly removed, and with a second needle, HRP was applied to the exposed part of the marginal zone in the caudal brain stem (see van Mier and ten Donkelaar, 1984).

Contacts between ingrowing axons and primary motoneurons. A total of 30 embryos of various stages $(27-40)$ were immobilized in a dish (as above), and the dorsal head skin as well as the skin covering myotomes 5-7 were removed. HRP was applied to the caudal brain stem (labeling descending axons) and simultaneously to the clefts between the myotomes. After HRP application, the embryos were freed from the table and left in fresh saline for $1 \mathrm{hr}$ (for healing of the skin) before they were rcturncd to a freshwater tank. To minimize the possible influence of HRP and the application procedure on the outcome of the experiments, the survival times were kept as short as possible, ranging from $1 \mathrm{hr}$ for stage 28 embryos up to (sometimes) $6 \mathrm{hr}$ for stage 40 embryos. The optimal survival time was determined for each stage separately as the time in which maximal labeling could be achieved for axonal growth cones in the absence of visible necrotic effects.

Tissue processing after fixation. At the end of the survival time, the embryos were deeply anesthetized with MS 222, fixed by immersion after removal of the skin on the experimental side in an ice-cold mixture of $2.5 \%$ glutaraldehyde and $1 \%$ formaldehyde in $0.1 \mathrm{M} \mathrm{Na}$-phosphate buffer ( $\mathrm{pH}$ 7.2). After $2 \mathrm{hr}$ the fixed specimens were transferred to fresh phosphate buffer and washed for an hour. Then the embryos were stained as a whole using the Adams' (1981) heavy metal intensification of the 3,3'-diaminobenzidine tetrahydrochloride technique (DAB) according to the following procedure (modified from Gaze and Fawcett, 1983):

1. After several washes in $0.1 \mathrm{M}$ Tris- $\mathrm{Cl}$ buffer (trishydroxyaminomethane, $\mathrm{pH} 7.2$ ), specimens were presoaked for $30-60 \mathrm{~min}$ in Trisbuffer containing $0.5 \% \mathrm{CoCl}_{2}(1 \%$ or more gives a high background in embryonic tissue);

2. following two $5 \mathrm{~min}$ washes in Tris buffer and one in phosphate buffer, the specimens were incubated (at $4^{\circ} \mathrm{C}$ ) for $30-60 \mathrm{~min}$ in $0.01-$ $0.05 \% \mathrm{DAB}$ (the younger the embryos, the lower the DAB concentration) in phosphate buffer containing $0.1-0.5 \%$ dimethyl sulfoxide (DMSO);

3. then the specimens were transferred to fresh $\mathrm{DAB}$-solution containing $\mathrm{H}_{2} \mathrm{O}_{2}\left(1 \mathrm{ml} 0.3 \% \mathrm{H}_{2} \mathrm{O}_{2} / 100 \mathrm{ml} \mathrm{DAB}\right.$ solution) and incubated for up to $90 \mathrm{~min}$ at $4^{\circ} \mathrm{C}$;

4. under visual control, the tcrmination point of the staining was determined and the reaction was stopped after a quick wash in glassdistilled water by either transferring the specimens to a $50 \%$ ethanol solution or to $1 \% \mathrm{OsO}_{4}$ in phosphate buffer for osmication.

The ethanol specimens were further dehydrated, mounted in cedarwood oil, and studied and drawn as whole mounts (van Mier et al.,
1985). The osmium-treated specimens were dehydrated through graded ethanol series ( 5 min steps), soaked in propylene oxide and a 1:1 propylene oxide-Epon 812 mixture, and finally embedded in Epon 812 . The embedded specimens were serially sectioned at $20 \mu \mathrm{m}$, mounted on glass slides (treated with repellent coating) on a hot plate (see also Fritzsch and Nikundiwe, 1984), and coverslipped with Epon 812 as mounting medium. The plastic sections were examined in the light microscope for contacts between labeled descending axons and primary motoneurons in the spinal cord. Although our intensification procedure of the HRP/DAB reaction offered some difficulty in the EM sections (heavy labeling), it greatly enhanced the visibility of possible contact sites in the thick sections which we needed for the first detection of such contacts. Some of the sectioned specimens containing such contacts were serially reconstructed according to Peter's oblique view reconstruction technique (Gaunt and Gaunt, 1978). Specific sections with contacts between identified labeled reticulospinal axons and motoneurons were then isolated from the coated slides after removal of the coverslip and re-embedded in Epon 812 for semithin and ultrathin cutting. Ultrathin sections were mounted on single hole or 75 mesh nickel or copper grids, contrasted with uranyl acetate and lead citrate, and examined in a Philips EM 300 or 310 .

The whole mounts and plastic sections were studied for ingrowing axons and contacts between these axons and primary motoneurons. The rates of axon growth were carefully estimated from the position of the HRP-labeled growth front with respect to the HRP application site. Drawings and photographs (using Ilford FP 4 film) were made with a Zeiss Universal microscope or with a Leitz microscope equipped with differential interference contrast optics (DIC). Photomicrographs were printed on Ilford Multigrade paper for optimal contrast.

\section{Electrophysiology}

In 32 embryos between stages 28 and 33, simultaneous recordings were made extracellulary from the ventral roots in the intermyotomal clefts and intracellularly from neurons in the caudal brain stem. Embryos were immobilized in saline (see above) containing $2 \times 10^{-5}$ to $10^{-4} \mathrm{M}$ tubocurarine-chloride (Sigma; see Kahn et al., 1982) and pinned on a small table.

Intracellular recordings. For recordings from brain-stem neurons, the dorsal head skin caudal to the otic vesicle was removed to expose the caudal part of the brain stem; and for the ventral root recordings, the lateral part of the skin caudal to the otic vesicle covering the rostral first 8 myotomes was removed. Micropipettes with resistances between $150-250 \mathrm{M} \Omega$ (when filled with $3 \mathrm{M} \mathrm{KCl}$ ) were pulled on a Brown-Flaming puller (Sutter Instr. Co.). When filled with 3\% Lucifer yellow dissolved in glass-distilled water, these electrodes measured resistances in excess of 500-600 M $\Omega$ and were beveled with a jetstream beveler (see Soffe and Roberts, 1982a) to approximately 250-350 M . Lucifer yellow (Sigma) was used for intracellular staining and identification of recorded cells which showed rhythmic activity during fictive swimming. Wellstained cells were obtained by leaving the electrode in the cell (without passing current) for 1-10 min. Best results were obtained when the embryos were fixed immediately after the experiment.

Ventral root recordings. Ventral root recordings were made with glass suction electrodes (40-60 $\mu \mathrm{m}$ tip diameter) applied to the intermyotomal clefts of the tail musculature (Kahn et al., 1982). In order to evoke fictive swimming (neural swimming in restrained animals) in the animal the dorsolateral and caudolateral part of the skin was stimulated, mechanically (with a sharp pin) or electrically (using $0.1 \mathrm{msec}$ current pulse), so that the peripheral axons of Rohon-Beard neurons were excited (Clarke et al., 1984).

After recording, the embryo was immediately removed from the dish and fixed in ice-cold 5\% glutaraldehyde solution in saline. After fixation the nervous system was freed of the surrounding tissues, dehydrated in graded ethanol series, cleared, and mounted in Fluormount and studied, drawn and photographed with a Zeiss Universal microscope equipped for fluorescence with incident illumination. For photography Kodak Tri-X (800 Asa) film was used with exposure times between 5 and 30 seconds.

\section{Results}

Embryonic development in the nonmotile and early swimming stage

Before presenting the results we will give a brief summary of the development of the embryonic musculature, its innervation, 

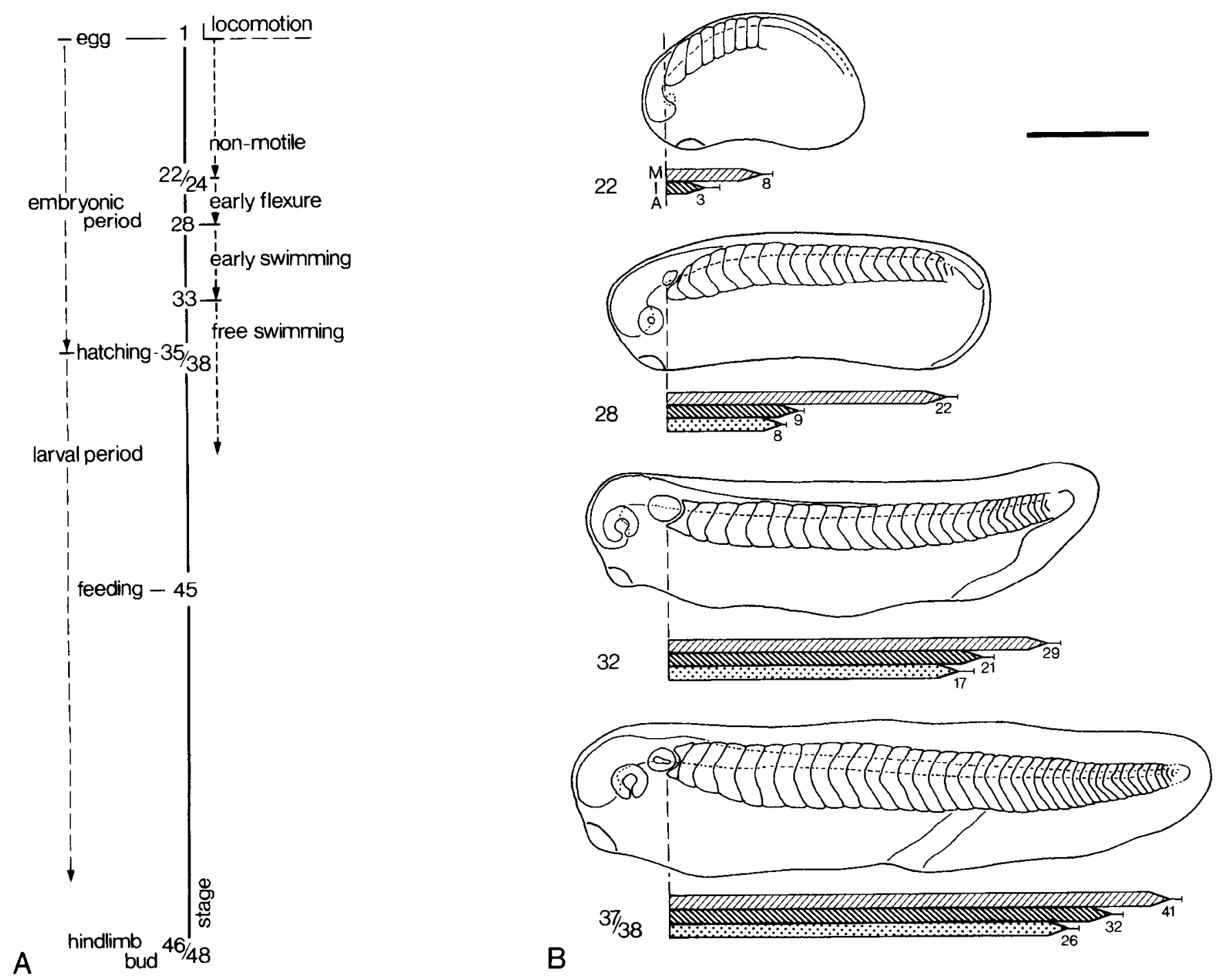

Figure 1. A, Development of tailswimming in Xenopus starts early during the embryonic period, beginning with the first random muscle contractions at the end of the nonmotile period (stages 22/24). In the early flexure stage, the embryos bend their heads upon skin stimulation; during the early swimming stage, the first short swimming episodes occur, while in the free-swimming stage, the embryos move freely through the water. $B$, Developing embryos continuously form new myotomes $(M)$ in rostrocaudal direction. Shortly after being formed, the myotomes become innervated $(I)$ by primary motoneuron axons from the spinal cord, after which, within hours, the first motor activity $(A)$ can be recorded from the innervated clefts between the myotomes (after van Mier et al., 1989). The numbers in the graphs below the embryos indicate observed maxima in the number of formed myotomes $(M)$, innervated intermyotomal clefts $(I)$, and myotomes from which motor activity $(A)$ could be recorded at different stages of development (see also Fig. 10A). Scale bar, $1000 \mu \mathrm{m}$.

and activation during the nonmotile and early swimming stages (based on van Mier et al., 1989: see Figs. 1 and 10A). In Xenopus embryos the first myotomes appear around stage 17, and in stage 40 embryos more than 40 myotomes have been formed. New myotomes become innervated within $12 \mathrm{hr}$ after formation, and newly formed neuromuscular synapses are activated within $4 \mathrm{hr}$ after formation. At the end of the nonmotile stage around stage 22 , when 6-8 myotomes are present, the first irregular contractions occur in the rostralmost myotomes. Around stage 29 (early swimming stage), when there are about 22 myotomes, the first spontaneous rhythmic swimming occurs. At stage 33 the embryos are free swimming and respond to external stimuli.

\section{Axonal ingrowth into the spinal cord}

After application of small quantities of HRP unilaterally to the marginal zone of the caudal brain stem, the growth of reticu- lospinal axons into the spinal cord was studied (Figs. $2 A$ and $10 A$, open stars). At stage $27 / 28$, when the first brain-stem neurons project to the spinal cord (van Mier and ten Donkelaar, 1984; van Mier et al., 1986), the first HRP-labeled axons could be seen to grow down, close to each other, through the spinal marginal zone. Often 1 or 2 axons were observed far ahead of the others and might be called "pioneer fibers" (for example, see Fig. $2 A$ ). The descending axons were usually observed in the ventral part of the marginal zone. The surface of the axons often appeared quite rough due to the many varicosities they contained. In some experiments, a single neuron and its descending axon were labeled so that the course of ingrowth followed by this axon could casily be studied (Fig. 4). Earlier findings from our immunohistochemical study on the development of serotonergic raphe-spinal projections (van Mier et al., 1986) are also presented in Figure 10A.

Axonal growth cones observed in early embryonic stages (27- 


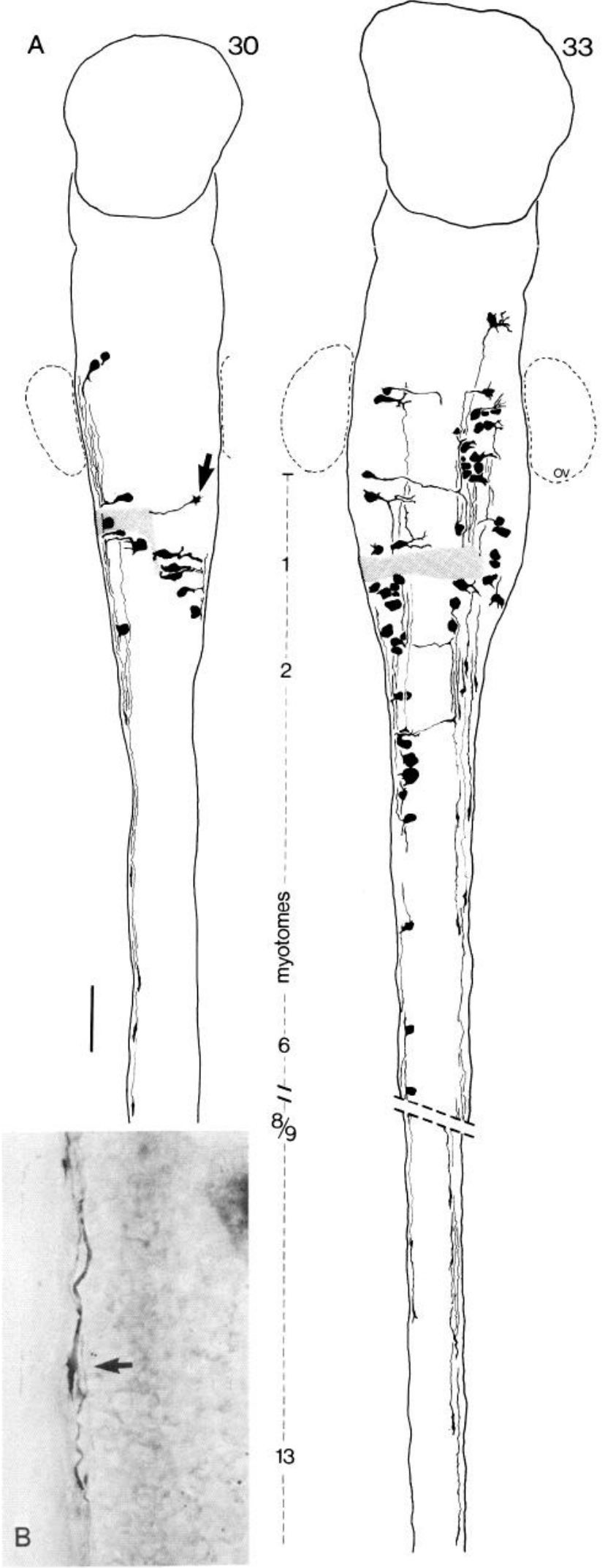

Figure 2. Descending axons of reticulospinal neurons in the brain stem observed during growth into the spinal cord. HRP was used as an anterograde tracer that was applied to the caudal brain-stem marginal zone at different stages during development. $A$, Examples of a stage 30 and a stage 33 embryo. Cross-hatchings indicate the site of HRP ap-
40) were often bulbous (varicose type) and sometimes slender or handshaped (lamellipodial type) with a variable number of filopodia (Figs. $2 A$, arrow, and 3 ). The dimensions of the growth cones observed between stages 27 and 40 are given in Figure $3 B$. Complex lamellipodial growth cones were more numerous near the growth front in younger stages, while the slender type appeared more frequently at older stages. Between stages 29 and 32 the lamellipodial type occurred approximately 1.5 times as often as the slender and varicose growth cones. At stage 40 most of the growth cones, especially in the spinal marginal zone, appeared slender or varicose.

The rate of ingrowth of these axons has been estimated from the progression of the ingrowing fibers between stages (see Fig. $10 B$ ). Between stages $29 / 30$ and 32 , when early swimming is developing, an increase in the growth rate was observed from $83 \mu \mathrm{m} / \mathrm{hr}(\mathrm{SEM}=24)$ to $210 \mu \mathrm{m} / \mathrm{hr}(\mathrm{SEM}=20)$. From our previous immunohistochemical observations we calculated the growth rates of raphe-spinal axons, which, being about $62 \mu \mathrm{m} /$ $\mathrm{hr}(\mathrm{SEM}=20)$ between stage 25 and 28 and $190 \mu \mathrm{m} / \mathrm{hr}$ (SEM $=19$ ) between stages 28 and 32, came close to our present HRP observations. Between stages 32 and 35, the growth rate of HRPlabeled axons appeared to decrease to $12 \mu \mathrm{m} / \mathrm{hr}(\mathrm{SEM}=6)$.

\section{Contacts between ingrowing axons and primary motoneurons}

In whole mounts and thick plastic sections of stage $27 / 28 \mathrm{em}-$ bryos (i.e., during the first ingrowth of axons into the spinal cord), descending axons and their growth cones could often be observed very close to the dorsal dendrites of the primary motoneurons (Figs. 5, 6). Thick sections were, before ultrathin resectioning for EM, serially reconstructed, which allowed identification of the position of the cell bodies from which the labeled ingrowing axons originated and the position of the labeled primary motoneurons they possibly contacted (Fig. $5 \mathrm{~A}$ ). Although most of the descending axons emerged from ipsilateral reticulospinal neurons, a few contralaterally projecting reticulospinal neurons were always observed (Figs. $2 A, 5$ ). In the spinal cord of stage 30 embryos, we occasionally observed (in LM and EM sections) contacts between descending reticulospinal axons and dendrites of the spinal motoneurons. At stage 33 more contact sites were observed, and approximately $70 \%$ of the light microscopically observed labeled axons that passed a motoneuron were found to contact one of its dendrites. The reticulospinal axons could be found contacting primary motoneurons anywhere on their dendritic trees, whereas the few observed descending axons of the contralateral projecting reticulospinal neurons almost exclusively made contact on the ventrolateral dendrites close to the soma of the primary motoneurons (Fig. $6, A, B)$. Possible contact sites were often found where varicosities were present in the descending axons. At stage 33 never more than one possible contact site could be observed between an axon and one motoneuron. However, EM sections at the sites of different motoneurons indicated that the same descending axon could contact many of them.

plication. In the brain stem, lammellipodial growth cones (arrow) could be observed, while in the spinal cord, predominantly slender and varicose growth cones were found. Scale bar, $1000 \mu \mathrm{m}$. B, Lamellipodial growth cone (arrow) in the spinal marginal zone. 

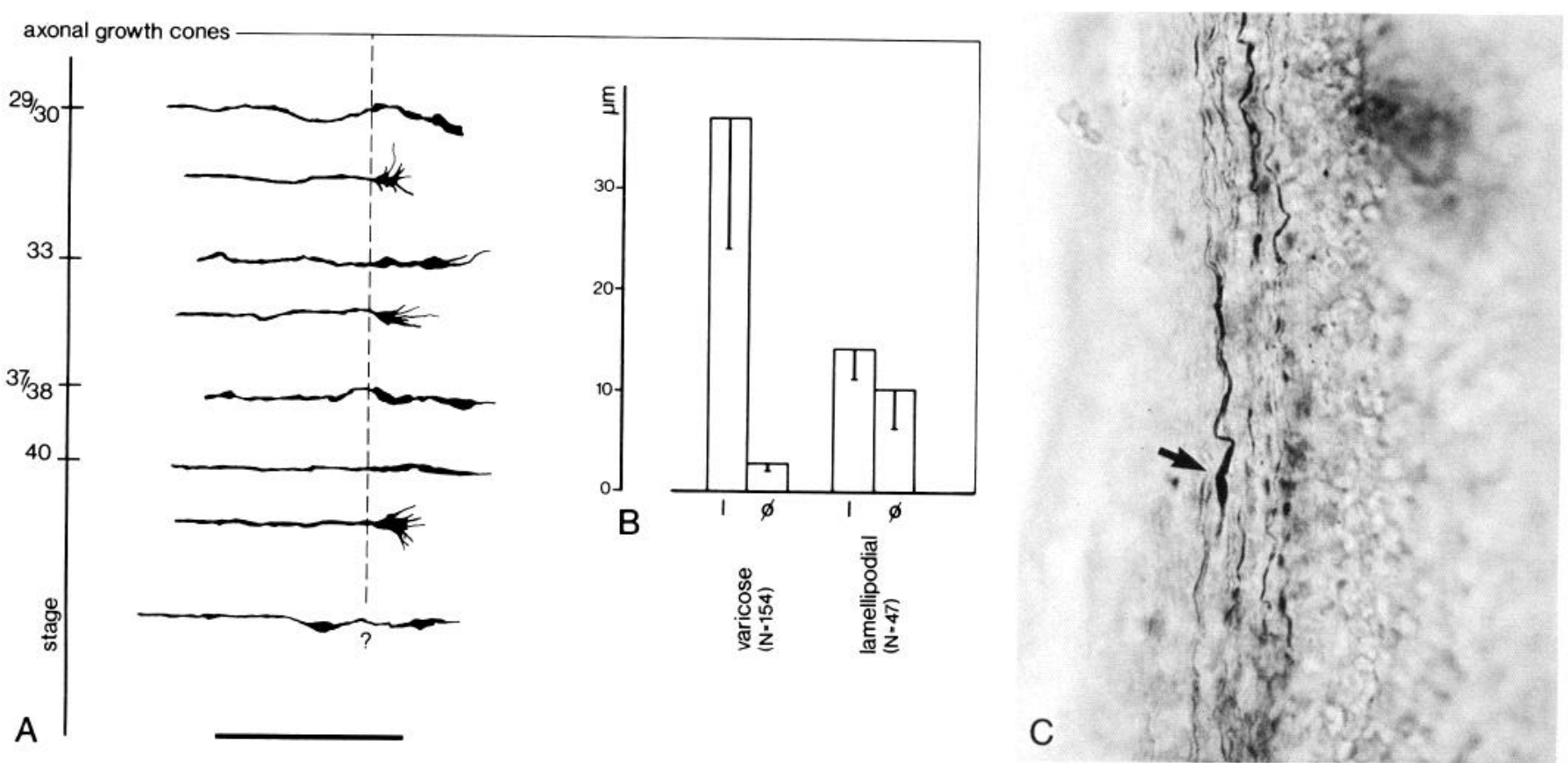

Figure 3. A, Various types of axonal growth cones observed in the spinal cord of stages $29 / 30-40$ embryos. It is not always clear what is and what is not part of the growth cone (? growth cone). Scale bar, $100 \mu \mathrm{m}$. $B$, Length $(l)$ and diameter $(\phi)$ plotted in microns for varicose and lamellipodial growth cones. $C$, Varicose growth cone (arrow) in the spinal cord.

In the EM material many chemical synapses containing synaptic vesicles were found in the unlabeled neuropil of the marginal zone between axons and structures (probably dendrites of primary motoneurons) perpendicular to the course of the axons (Fig. 6C). Where labeled axons were found to contact primary motoneuron dendrites, a small cleft was always present (Fig.
$6 D$ ). Presynaptic vesicles were observed at 12 of 68 of these sites. The low incidence of observed vesicles was probably due to masking by the heavy electron-dense label. In stage 33 spinal cord preparations the contact sites appeared very simple, without any axonal protrusions embracing motoneuron dendrites.

Many labeled growth cones were observed descending along
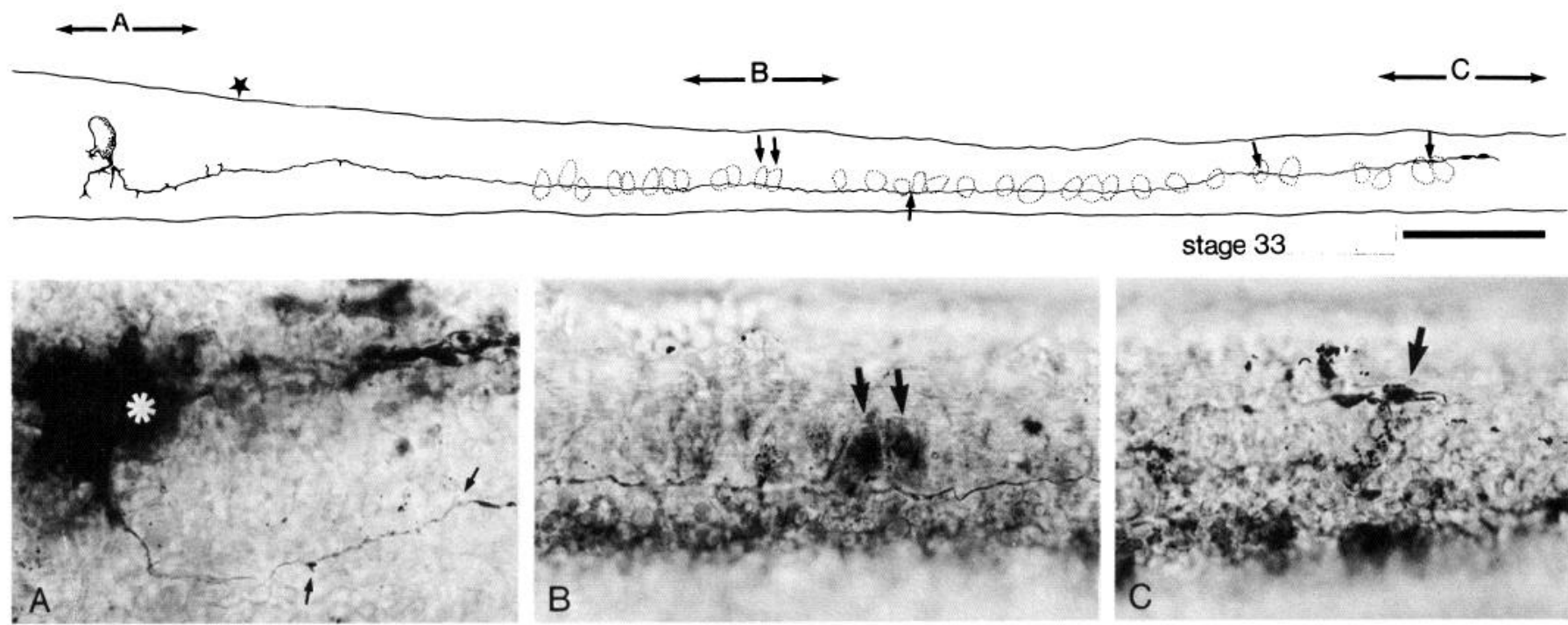

Figure 4. Morphology of a single reticulospinal neuron and its descending axon growing down the spinal cord labeled after application of HRP with a tungsten needle to the caudal part of the brain stem. Lateral view of the whole mount showing the descending axon in the spinal marginal zone. Primary motoneurons which could be observed in the background are dotted. At some sites where the descending axons grew along the motoneuron surface some small protrusions could be observed (arrows). Parts of this neuron are shown in the photomicrographs below. $A$, Distal part of the varicose descending axon close to the soma, small protrusions are present on its surface (arrows). Asterisk indicates HRP-application site. $B$, Middle part of the axon growing along the surface of 2 primary motoneurons (arrows). $C$, The varicose growth cone (arrow) at the level of the 12 th myotome. Scale bar, $100 \mu \mathrm{m}$. 


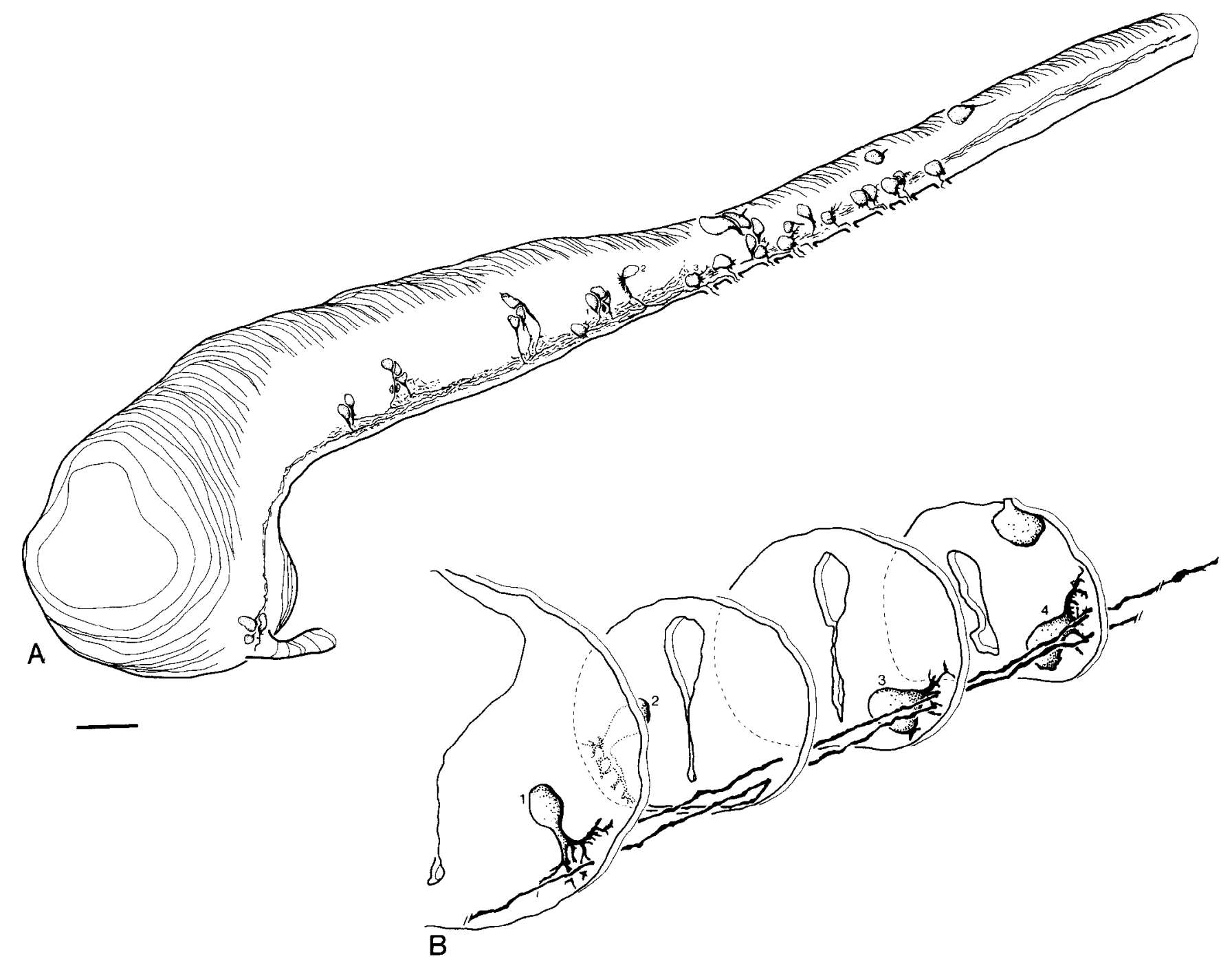

Figure 5. Serial reconstruction of transversely sectioned CNS of a stage 33 embryo. In a double experiment HRP was applied simultaneously to the caudal brain stem and the 5 th and 6 th myotome. $A$, Lateral view of the reconstructed CNS. In the rostral spinal cord some primary motoneurons and some Rohon-Beard cells could be observed. In the brain stem, HRP labeled ipsi- and contralaterally projecting reticulospinal neurons were found. $B$, Four sections taken from the reconstruction showing an identified ipsilaterally $(I)$ and contralaterally projecting reticulospinal neuron (2). The descending axons of these identified reticulospinal neurons could be traced into the spinal cord where they contacted 2 primary motoneurons $(3,4)$. Scale bar, $100 \mu \mathrm{m}$.

the spinal cord usually close to the lateral border of the marginal zone. Often, large spaces could be observed between the descending axons in the marginal zone. Sometimes small protrusions, probably filopodia, were seen emerging from the growthcone surface (Fig. 6E).

\section{Role of reticulospinal neurons during fictive swimming}

Physiology. In 22 embryos between stages 28 and 40, some 56 neurons in the caudal brain stem were successfully penetrated and recorded intracellularly; 27 of them were labeled with Lucifer yellow (Fig. 7). Without exception the recorded brain-stem neurons were found in the ventromedial part of the brain stem, i.e., the reticular formation (Fig. 8; see van Mier and ten Donkelaar, 1984). At stage 30, the first caudal brain-stem neurons were found to be active during fictive swimming with phasic "motoneuron-like" activity, i.e., one spike per swimming cycle (cf. Soffe and Roberts, 1982a; Dale and Roberts, 1985). In older stages finding neurons with phasic swimming-related activity became progressively easier. The penetrated cells showed resting potentials of $-40 \mathrm{mV}$ or more. The maximum recorded resting potential was $-78 \mathrm{mV}$, measured at the end of the recording. During swimming (if this could be evoked by skin stimulation), the onset of a swimming episode could be preceded by either a gradual (Fig. $8 B$ ) or a sudden depolarization (Fig. $8, A, C$ ). This sustained depolarization was maintained between 5 and $30 \mathrm{mV}$ above resting membrane potential during the whole swimming episode duration. Identified reticulospinal neurons fired either in phase or in antiphase with the ipsilateral ventral root motor discharges (Fig. 9A). Reticulospinal neurons which fired in phase ( $n=23$ ) with the ipsilateral ventral root discharge had one spike per swimming cycle with a phase lead of $0.0-0.1$. Some reticulospinal neurons $(n=4)$ fired in alternation (counterphase) with the ipsilateral motor nerve bursts, with a phase lead of $0.5-0.6$.

At the end of a swimming episode, the recorded membrane potential returned through a gradual repolarization to its resting 

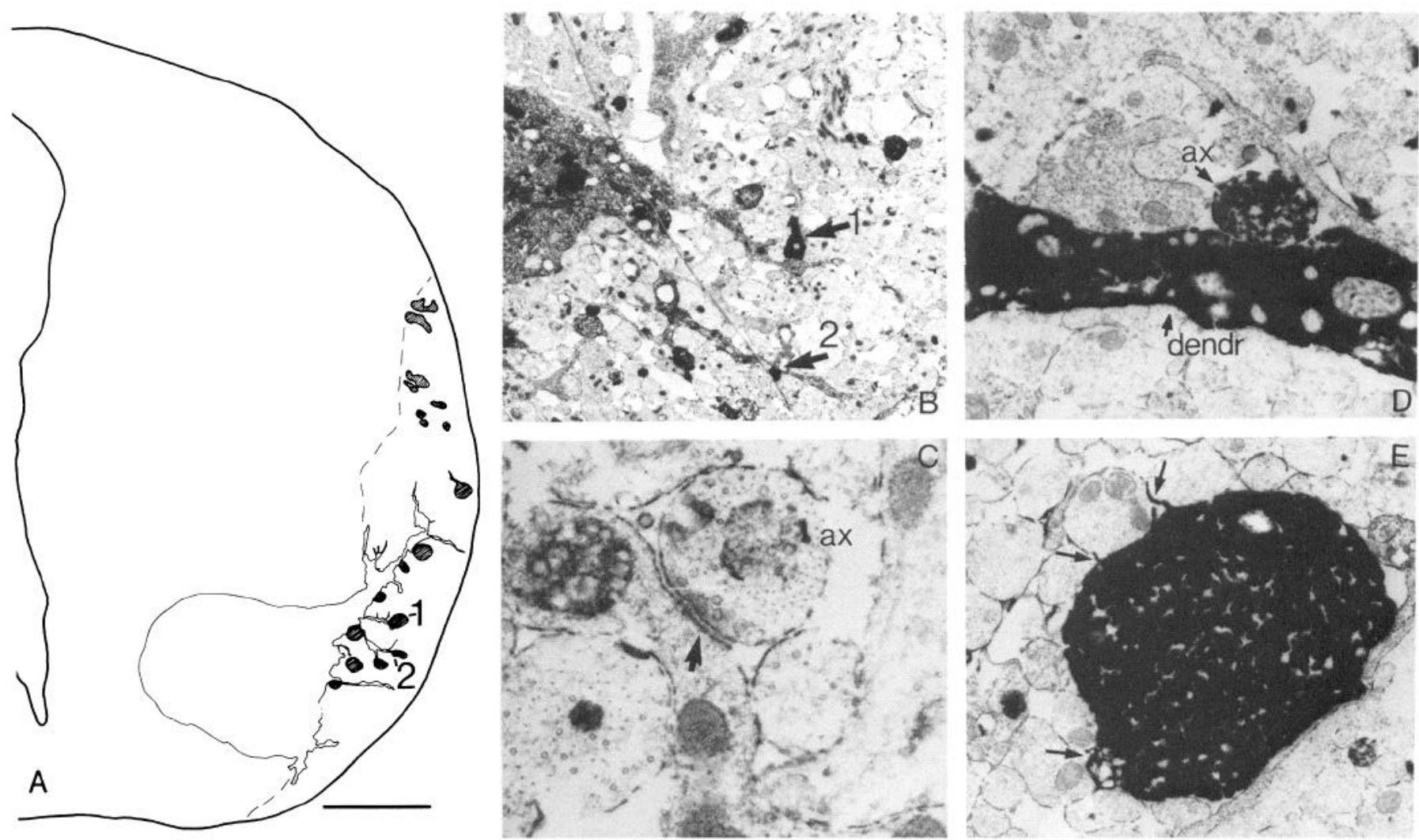

Figure 6. A, Transverse section of primary motoneuron (3 from Fig. 5). The hatched profiles are HRP-labeled descending reticulospinal axons. The numbered axons $(I$ and 2$)$ correspond with the neurons shown in Figure 5. B. Electron micrograph showing the sites where the descending axons of the reticulospinal neurons $(I, 2)$ contacted dendrites of this primary motoneuron. $C$, Chemical synapse with postsynaptic density (arrow) between an axon and an identified dendrite. $D$, Descending axon contacting a labeled primary motoneuron dendrite. $E$, Transverse section of a growth cone with some small protrusions emerging from its surface (arrows). Scale bar, $10 \mu \mathrm{m}$.

potential. Short repolarizations were observed between spikes (Fig. 8B, arrows; see also Roberts and Kahn, 1982; Soffe and Roberts, 1982a). Short delays of 2-10 msec were observed between intracellularly recorded spikes in brain-stem neurons and subsequent nearby ventral-root discharges.

Morphology. The Lucifer yellow-labeled neurons in the caudal brain stem were similar to reticulospinal neurons as described in HRP studies by van Mier and ten Donkelaar (1984) and Nordlander et al. (1985) or immunohistochemical studies by van Mier et al. (1986). In all cases an ipsilateral descending axon (to the spinal cord) was present. The descending axons of the Lucifer yellow injected cells were always quite rough and contained many varicosities. Seven neurons also had an ascending fiber (and in 2 cases two) extending into the rostral brain stem as far as the level of the trigeminal nerve (Fig. 8, $A, B$ ). The labeled neurons extended their dendrites into the fiber mass of the ventrolateral marginal zone. Axons of these labeled brainstem neurons projected to the same spinal levels as observed in the HRP experiments (Fig. 10A, open stars). The axons were never observed to leave the spinal cord and usually ended in a growth cone; thus, the labeled neurons were not primary motoneurons with long centrally descending axons.

\section{Discussion}

In this study we investigated the ingrowth of supraspinal axons from the brain stem into the spinal cord and the activity of reticulospinal neurons during swimming. The results of this and a related paper (van Mier et al., 1989) are summarized in Figures 1,10 , and 11 .

\section{General considerations on reticulospinal neurons}

In vertebrates reticulospinal pathways differentiate early in development. In Xenopus embryos, developing lamprey (Rovainen, 1978, 1979), larval zebrafish (Kimmel, 1982), developing chick (Okado and Oppenheim, 1985), and young opossum (Cabana and Martin, 1984), reticulospinal neurons in the caudal brain stem are the first that project to the spinal cord (van Mier and ten Donkelaar, 1984; Nordlander et al., 1985; van Mier et al., 1986).

In early Xenopus embryos reticulospinal neurons with ipsilateral descending axons were found in the caudal part of the brain stem and appeared to resemble the descending interneurons previously found and described in spinal cord and brain stem of Xenopus embryos (Roberts and Clarke, 1982; Roberts et al., 1983; Roberts and Alford, 1986). We also observed reticulospinal neurons with contralateral descending axons that resembled the spinal commissural interneurons described by Roberts and Clarke (1982) and Dale et al. (1986). T reticular interneurons with contralateral descending axons have recently been described in the developing brain stem of the zebrafish (Kimmel et al., 1985; Mendelson, 1986; Metcalfe et al., 1986). However, serial repetition of reticulospinal neurons of either class as described for $\mathrm{T}$ reticular interneurons in the embryonic zebrafish brain stem have not yet been observed in Xenopus embryos. 


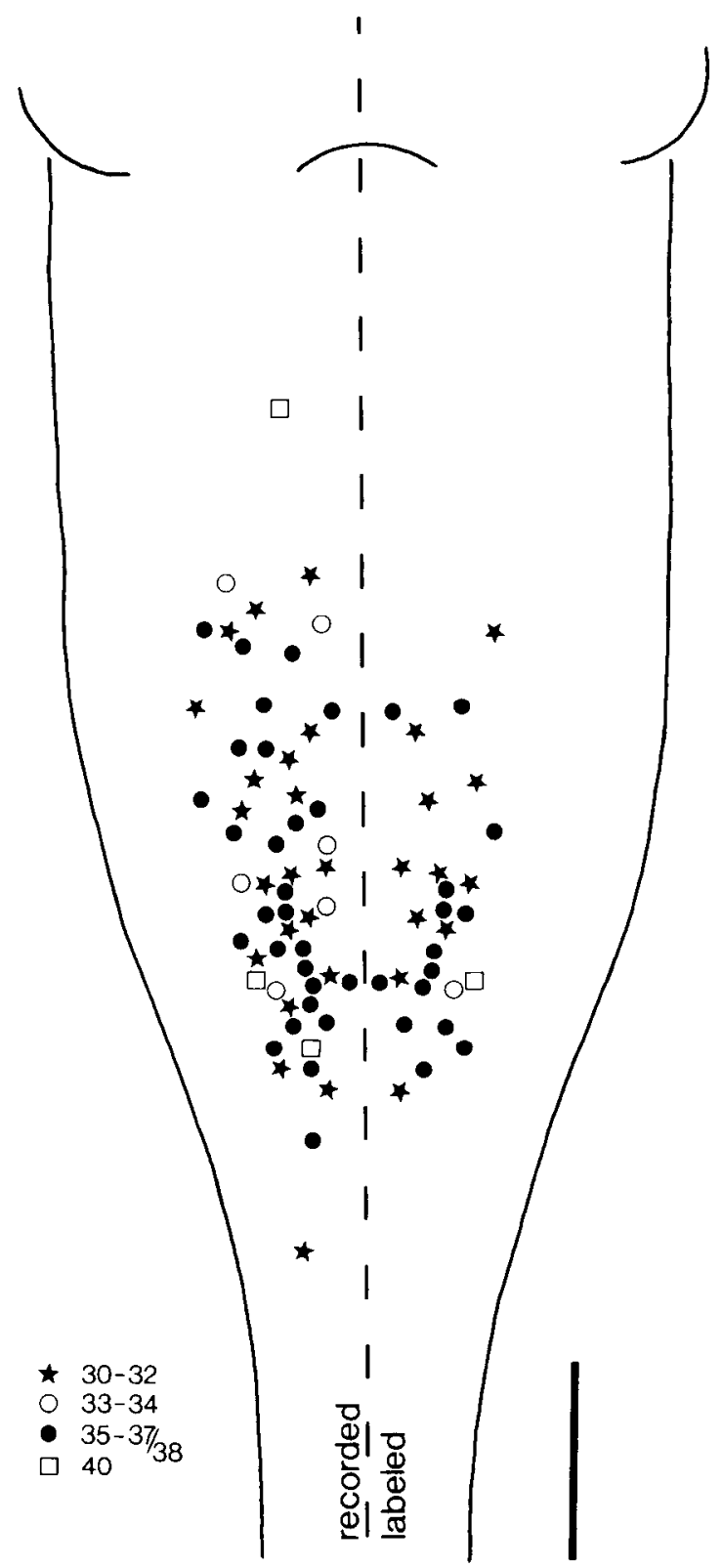

Figure 7. Distribution of sites where intracellular recordings were made from cells that were phasically active during swimming (left side). On the right side are all the cells plotted which were also intracellularly labeled with Lucifer yellow.

Whether reticulospinal neurons form a separate population of interneurons in the CNS and whether this is of consequence in understanding the principles of locomotor control is unclear. In Xenopus embryos reticulospinal neurons are organized in longitudinal populations (van Mier and ten Donkelaar, 1984; Nordlander et al,, 1985) that are continuous with the columns of descending interneurons in the spinal cord (see van Mier, 1988). The morphology of reticulospinal neurons and spinal descending interneurons (Roberts and Alford, 1986) is so similar that they can hardly be distinguished from each other. Interneurons, defined by Rakic (1975) as all neurons which are "neither motor nor sensory," were divided by Bullock et al. (1977) into (1) projecting interneurons, (2) commissural interneurons (actually a special class of projecting interneurons), and (3) intrinsic interneurons. In our case, reticulospinal interneurons and descending interneurons would form a continuous population of projecting interneurons from the brain stem into the spinal cord. Accordingly, the function of this population in locomotion might be similar for cells in the rostral or the caudal part of this population so that we can speak of descending interneurons with a different location but with a similar function.

\section{Early axonal ingrowth}

In the early-swimming stage in $X$. laevis embryos, the first, seemingly random, muscle contractions develop into real swimming movements, i.e., alternating undulating muscle contractions on both sides of the body (van Mier et al., 1989). The first ingrowth of axons from the brain stem to the spinal cord occurs quite early during development. A summary of these events is given in Figure 11. The axons originate from large basal plate cells, i.e., reticulospinal neurons in the caudal brain stem (sce Forchand and Farel, 1982; van Micr and ten Donkelaar, 1984; Nordlander et al., 1985; van Mier et al., 1986). These reticulospinal neurons are among the first neurons to be determined during gastrulation (Lamborghini, 1980; van Mier, 1986). Between stages $27 / 28$ and 32 approximately 75 fibers descend through the marginal zone on either side of the spinal cord. Between stages 29/30 and 32 the maximum rate of axon growth coincides with the appearance of rhythmic swimming movements along the myotomal musculature. The values we found are higher than the initial growth rates (stage 22-24) observed for ventral longitudinal and other early neurons by Jacobson and Huang (1985), who, by labeling cells before they start to differentiate (Jacobson and Hirose, 1981; Hirose and Jacobson, 1981), could study the initial outgrowth of neurites. At stage 35 many descending axons have reached the level of the 15 th myotome with an occasional fiber extending as far down as the level of the 18 th myotome. This observation is in keeping with findings of Nordlander et al. (1985), who reported that supraspinal input to the tail spinal cord, i.e., caudal to the 15 th myotome, was first observed between stages 35 and 37 .

Here, it should be mentioned that experimental conditions might affect the quantification of axonal growth. Application of too much HRP (P. van Mier, unpublished observations and Nordlander, 1987) or long survival times may cause toxic effects that result in axonal degeneration. While testing our HRP technique, we found that with long survival times after HRP application, the growth rates for the descending axons slightly decreased; thus, we used the shortest possible survival times. In comparing our HRP results with previous immunohistochemical data on the development of serotonergic reticulospinal neurons (van Mier et al., 1986), we found that between stages 28 and 32 the estimated growth rate of HRP-filled axons comes close to the rate calculated for growing serotonergic axons. The growth fronts of serotonergic and HRP-labeled axons (this study) occurred at similar levels at the same time during development. This and the similar morphology of immunohistochemically and, in this study, HRP-or Lucifer yellow-labeled reticulospinal neurons suggests that our HRP applicaton procedure or the chronic presence of very small quantities of HRP (using the shortest possible survival time) does allow careful study of axonal growth in developing embryos.

Our HRP data suggest an increased growth rate of descending fibers between stages $29 / 30$ and 33, which, if genuine, might be 


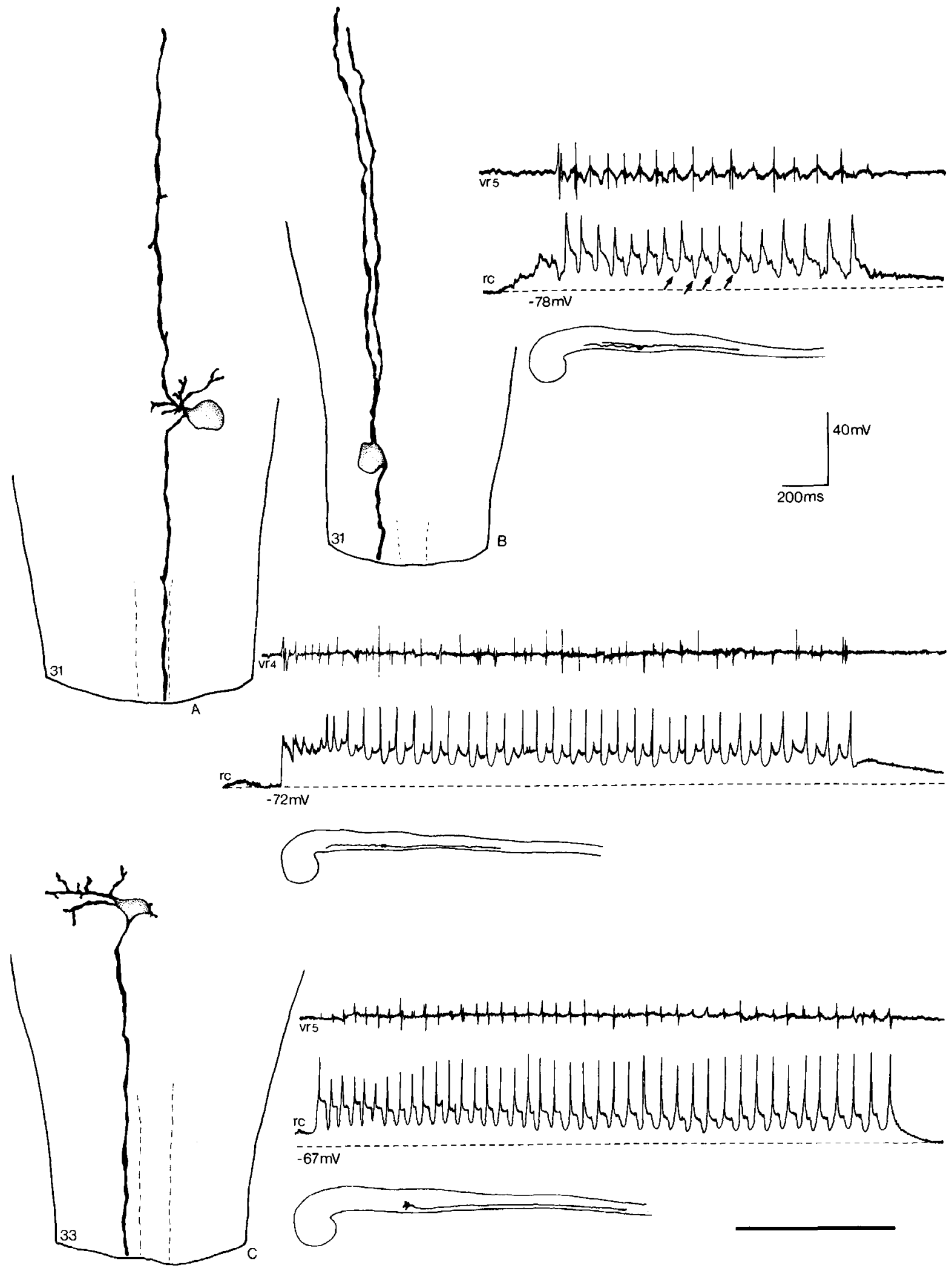

Figure 8. Three intracellularly labeled reticulospinal neurons in the caudal brain stem and their activity (lower trace) recorded simultaneously with ipsilateral ventral root activity (upper trace) during fictive swimming. Besides a descending axon, $2(A, B)$ also have ascending branches extending into the upper brain stem. One of the reticulospinal neurons $(C)$ showed only a descending axon and some short dendrites that extended, at the level of the soma, into the marginal zone. $r c$, reticulospinal cell; $v r$, ventral root. Scale bar, $100 \mu \mathrm{m}$. 


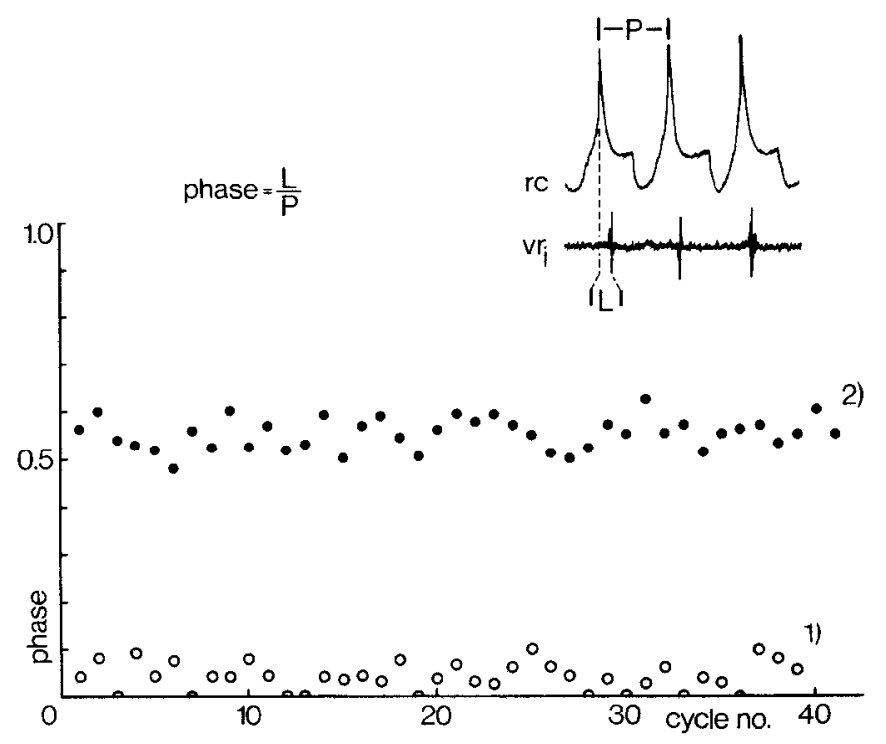

Figure 9. Phase relations of ventral root discharges and activity of reticulospinal neurons during successive cycles of a swimming episode. Reticulospinal neurons fired their spikes either in phase $(I)$ or in antiphase (2) with the ipsilateral motor nerve activity. The latency of the ventral root discharges $(L)$ is expressed as a fraction of the swimming cycle period $P$ (see recording).

explained in terms of production, presence, and distribution of nerve growth factors, nerve cell adhesion molecules (NCAM; for Xenopus, see Jacobson and Rutishauser, 1986), more favorable terrain, and the presence of electric fields in vertebrate embryos (Jaffe, 1985). Directed growth in electrical fields has been shown by Jaffe and Poo (1979), Hinkel et al. (1981), Patel and Poo (1982), and McCaig (1986, 1987). McCaig(1986) showed that early spinal neurite outgrowth in Xenopus spinal cord cultures was 2-3 times more rapid in a negative electric field. In Xenopus, active motoneurons might produce electric fields which could cause electrically directed growth (Jaffe, 1985) in descending axons. However, Haverkamp and Oppenheim (Haverkamp, 1986; Haverkamp and Oppenheim, 1986) proposed that early development of specific neuronal morphology and connectivity does not depend on functional activity. Although their immobilized Xenopus embryos showed no permanent effects after drug removal, the observed transient decrease in response to tactile stimuli or in swimming episode duration may have been caused by a decrease in central connectivity during early development.

Many of the synapses we observed between descending reticulospinal axons and primary motoneurons showed no postsynaptic density, while some had one. Since the acquisition of presynaptic vesicles seems to precede the appearance of the postsynaptic density during synaptic development (Bodian, 1968; Hayes and Roberts, 1974; for review, see Purves and Lichtman, 1985), we assume that the chemical synapses we observed were

Figure 10. A, Summary of the development of myotomes (e), the innervation of these myotomes $(\star)$, the onset of ventral root activity (O), and the ingrowth of reticulospinal axons into the spinal cord ( $(5)$ ). For comparison, some results concerning the ingrowth of serotonergic raphe-spinal axons $(*)$ are also presented (taken from van Mier et al.,

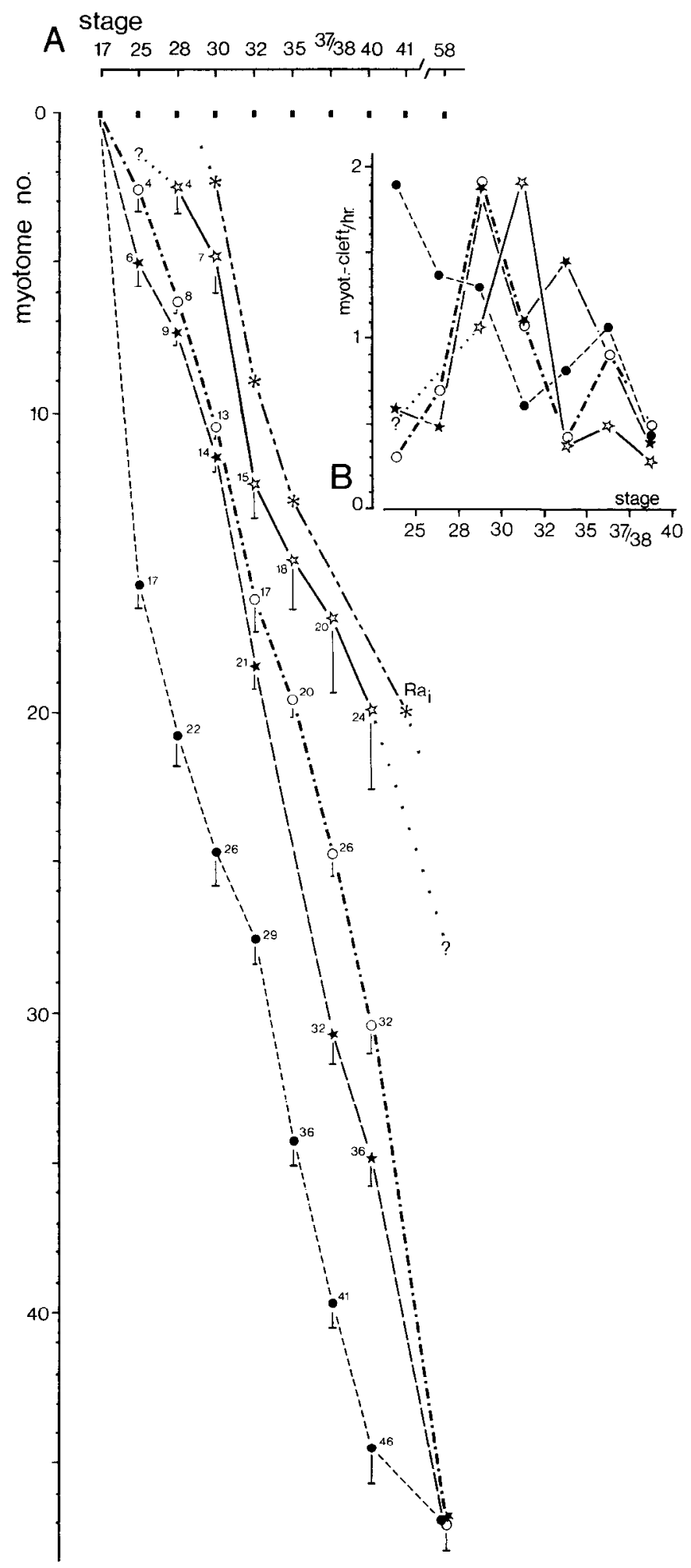

1986). The levels are indicated by the number of the myotomes adjacent to the front of the ingrowing reticulospinal axon bundle. The small numbers in the graph indicate the observed maxima at different stages of development. SEM are indicated with vertical bars. $R a_{i}$, nucleus raphes inferior. $B$, During the embryonic early swimming stage, between stages 28 and 32 , the rate of myotome formation appears to decrease gradually, while the rates of myotome innervation and activation and the rate of reticulospinal axon ingrowth appear to increase. 

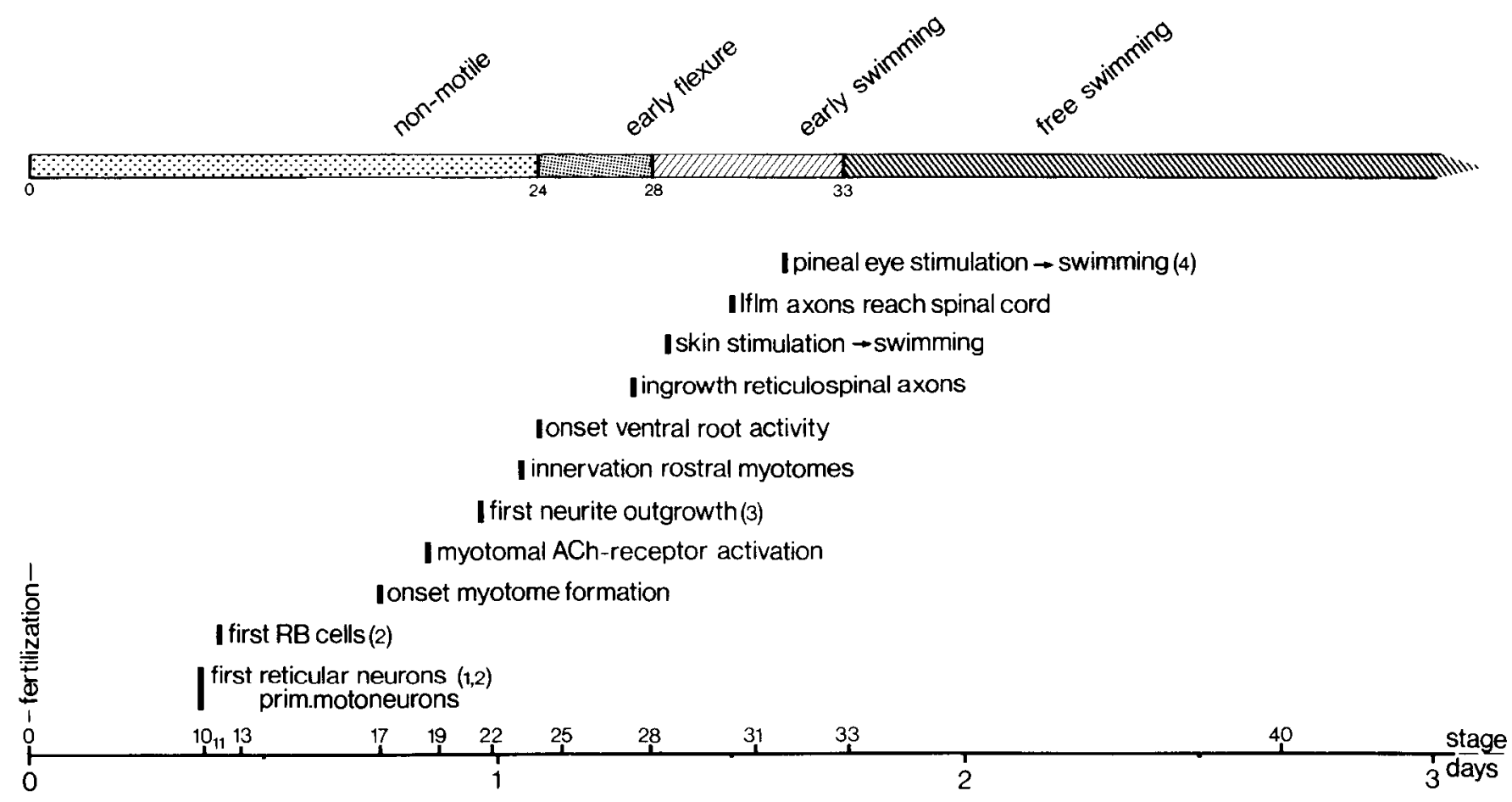

Figure 11. Timetable summarizing the events "leading" to early swimming in Xenopus embryos. The vertical bars mark the first occurrence of different events. Other sources of information have been used and are indicated between brackets: (1) van Mier (1986); (2) Lamborghini (1980); (3) Jacobson and Huang (1985); and (4) Foster and Roberts (1982). ACh, acetylcholine; Iflm, mesencephalic reticular nucleus, origin of the medial longitudinal fasciculus (see van Mier and ten Donkelaar, 1984); $R B$ cells, Rohon-Beard cells.

newly formed and possibly already active. In this respect it is noteworthy that Takahashi et al. (1987) recently showed that developing neuromuscular junctions in cultures of dissociated muscle cells and neurons from Xenopus embryos were active shortly after formation (4-11 hr), while no postsynaptic density was found.

In Xenopus a few types of axonal growth cones have been observed (Jacobson and Huang, 1985; Nordlander, 1987). The growth cones we observed had an average length of $31 \mu \mathrm{m}$, which matched the growth cones of raphe-spinal axons (length, 10-30 $\mu \mathrm{m}$; van Mier et al., 1986), but were seldom as small (4$6 \mu \mathrm{m})$ as those reported by Nordlander and Singer (1982) in stages $28-40$ embryos. The shortest were the lamellipodial growth cones, ranging from 5 to $20 \mu \mathrm{m}$. Many growth cones were bulbous, with few filopodia and quite similar to the varicose growth cones observed at the growing tips of peripheral outgrowing axons of spinal motoneurons (Moody and Jacobson, 1983; Tosney and Landmesser, 1985; van Mier and ten Donkelaar, 1985; van Mier et al., 1985; Myers et al., 1986). Lamellipodial growth cones with many filopodia (see Bray, 1982; Nordlander, 1987) were also observed, usually close to the growth front and more abundantly in younger than in older embryos. The target finding by descending fibers, i.e., contacting primary motoneurons, seems relatively simple since once set on their way the descending fibers only have to grow along the spinal cord, where the motoneurons are neatly arranged in longitudinal columns. Since in the brain stem, where target finding might be more difficult, more lamellipodial growth cones are observed (P. van Mier, unpublished observations; see Fig. $2 A$, arrow), it is suggested that this type of growth cone is developed in more complex, or decision, areas (see Tosney and Landmesser, 1985; Bovolenta and Mason, 1987), whereas varicose and slender growth cones predominantly appear in more easy areas (for growth cone motility see Letourneau, 1985).

\section{Reticulospinal neurons and early swimming}

From this study it has become clear that reticulospinal neurons participate in early swimming. During early locomotion they have "motoneuron-like" activity, producing one spike per swimming cycle (van Mier, 1986, 1987). Their activity during swimming shows a similarity to that reported for large reticulospinal neurons (Müller cells) in the lamprey, which are also active during cach swimming cycle (Kasicki and Grillncr, 1986).

With their long descending axons projecting to the spinal cord, these reticulospinal neurons closely resemble the spinal interneurons described by Roberts and Clarke (1982). It has been proposed by Dale and Roberts (1985) that in $X$. laevis ipsilateral descending interneurons in the spinal cord of stage $37 / 38 \mathrm{em}-$ bryos might exert an excitatory drive upon primary motoneurons. In lesion experiments (i.e., hemisection of the CNS at various levels), Soffe (1985) and Roberts and Alford (1986) showed electrophysiologically that descending interneurons might play an important role in sustaining of swimming. Reticulospinal neurons might participate in this activity. In a related paper (van Mier et al., 1989) we propose that at least 610 rostral spinal segments and adjacent myotomes are needed for rhythmic swimming, i.e., the number of segments actually invaded by reticulospinal axons between stages $29 / 30$ and 32 . Lesion experiments (Roberts and $\Lambda$ lford, 1986) have shown that the caudal brain stem and rostral spinal segments have an important influence on the initial swimming frequency and the duration of the swimming episodes. Furthermore, in this period 
in the rostral spinal cord, many axodendritic synapses have been observed by Hayes and Roberts (1974). Our findings indicate the presence of (probably functional) contacts between descending axons and primary motoneurons. Altogether it seems quite likely that a population of descending "interneurons," i.e., reticulospinal neurons, in the brain stem and descending interneurons in the spinal cord (Dale and Roberts, 1985), and the contacts their axons have developed with primary motoneurons, are important for the development and control of early swimming. In Xenopus embryos reticulospinal neurons appear to form part of the central swimming pattern generator rather than driving or controlling it.

We conclude that (1) reticulospinal neurons are rhythmically active during early fictive swimming, (2) the growth of reticulospinal axons occurs during the devclopment of early swimming, (3) the descending axons contact primary motoneurons, and (4) reticulospinal neurons in the brain stem closely resemble spinal descending interneurons with which they may form a population of projecting interneurons having a similar function but different location.

\section{References}

Adams, J. C. (1981) Heavy metal intensification of DAB-based HRP reaction product. J. Histochem. Cytochem. 29: 775 .

Babalian, A. L., and N. M. Chmykhova (1987) Morphophysiological characteristics of connexions between single ventrolateral tract fibers and individual motoneurons in the frog spinal cord. Brain Res. 407: 394-397.

Babalian, A. L., and A. I. Shapovalov (1984) Synaptic actions produced by individual ventrolateral tract fibers in frog lumbar motoneurons. Exp. Brain Res. 54: 551-563.

Bodian, D. (1968) Development of fine structure of spinal cord in monkey fetuses. J. Comp. Neurol. 133: 113-166.

Bovolenta, P., and C. Mason (1987) Growthcone morphology varies with position in the developing mouse visual pathway from retina to first targets. J. Neurosci. 7: 1447-1460.

Bray, D. (1982) The mechanism of growth cone movements. Neurosci. Res. Prog. Bull. 20: 821-829.

Bullock, T. H., R. Orkand, and A. Grinnell (1977) Introduction to Nervous Systems, Freeman, New York.

Cabana, T., and G. F. Martin (1984) Developmental sequence in the origin of descending spinal pathways. Studies using retrograde transport techniques in the North American Opossum (Didelphis virginiana). Dev. Brain Res. 15: 247-263.

Clarke, J. D. W., B. P. Hayes, S. P. Hunt, and A. Roberts (1984) Sensory physiology, anatomy and immunohistochemistry of RohonBeard neurones in embryos of Xenopus laevis. J. Physiol. (Lond.) 348: 511-525.

Coghill, G. E. (1929) Anatomy and the Problem of Behavior, Cambridge U.P., Cambridge.

Cruce, W. L. R. (1974) A supraspinal monosynaptic input to the hindlimb motoneurons in the lumbar spinal cord of the frog, Rana catesbeiana. J. Neurophysiol. 37: 691-704.

Dale, N. (1985) Reciprocal inhibitory interneurones in the Xenopus embryo spinal cord. J. Physiol. (Lond.) 363: 61-70.

Dale, N., and A. Roberts (1985) Dual component amino-acid-mediated synaptic potentials: Excitatory drive for swimming in Xenopus embryos. J. Physiol. (Lond.) 363: 35-59.

Dale, N., O. P. Ottersen, A. Roberts, and J. Storm-Mathisen (1986) Inhibitory neurones of a motor pattern generator in Xenopus revealed by antibodies to glycine. Nature 324: 255-257.

Forehand, C. J., and P. B. Farel (1982) Spinal cord development in anuran larvae. II. Ascending and descending pathways. J. Comp. Neurol. 209: 395-408.

Foster, R. G., and A. Roberts (1982) The pineal eye in Xenopus laevis embryos and larvae: A photoreceptor with a direct excitatory effect on behavior. J. Comp. Physiol. 145: 413-419.

Fritzsch, B., and A. M. Nikundiwe (1984) Studying nervous connectivity in wholemount brains of small animals using horseradish peroxidase. Mikroskopie (Wien) 41: 145-149.
Gaunt, W. A., and P. N. Gaunt (1978) Three Dimensinal Reconstruction in Biology, Pitman Medical, London.

Gaze, R. M., and J. W. Fawcett (1983) Pathways of Xenopus optic fibres regenerating from normal and compound eyes under various conditions. J. Embryol. Exp. Morphol. 73: 17-38.

Grillner, S. (1981) Control of locomotion in bipeds, tetrapods, and fish. In Handbook of Physiology-The Nervous System, Vol. 2, Motor Control, V. Brooks, ed., pp. 1179-1236, American Physiology Society, Bethesda, MD.

Haverkamp, L. J. (1986) Anatomical and physiological development of the Xenopus embryonic motor system in the absence of neural activity. J. Neurosci. 6: 1338-1348.

Haverkamp, L. J., and R. W. Oppenheim (1986) Behavioral development in the absence of neural activity: Effects of chronic immobilization on amphibian embryos. J. Neurosci. 6: 1332-1337.

Hayes, B. P., and A. Roberts (1974) The distribution of synapses along the spinal cord of an amphibian embryo: An electron microscope study of junction development. Cell Tissue Res. 153; 227-244.

Hinkel, L., C. D. McCaig, and K. R. Robinson (1981) The direction of growth of differentiating neurones and myoblasts from frog embryos in an applied electric field. J. Physiol. (Lond.) 314: 121-135.

Hirose, G., and M. Jacobson (1981) Clonal organization of the central nervous system of the frog. I. Clones stemming from individual blastomeres of the 16-cell and earlier stages. Dev. Biol. 71: 191-202.

Jacobson, M., and G. Hirose (1981) Clonal organization of the central nervous system of the frog. II. Clones stemming from individual blastomeres of the 32- and 64-cell stages. J. Neurosci. 3: 271-284.

Jacobson, M., and S. Huang (1985) Neurite outgrowth by means of horseradish peroxidase inherited from neuronal ancestral cells in frog embryos. Dev. Biol. 110: 102-113.

Jacobson, M., and U. Rutishauser (1986) Induction of neural cell adhesion molecule (NCAM) in Xenopus embryos. Dev. Biol. 116: $524-531$.

Jaffe, L. F. (1985) Extracellular current measurements with a vibrating probe. TINS 8: 517-521.

Jaffe, L. F., and M.-M. Poo (1979) Neurites grow faster towards the cathode than the anode in a steady field. J. Exp. Zool. 209: 115-128.

Kahn, J. A., A. Roberts, and S. M. Kashin (1982) The neuromuscular basis of swimming movements in embryos of the amphibian Xenopus laevis. J. Exp. Biol. 99; 175-184.

Kasicki, S., and S. Grillner (1986) Müller cells and other reticulospinal neurones are phasically active during fictive locomotion in the isolated nervous system of the lamprey. Neurosci. Lett. 69: 239-243.

Kimmel, C. B. (1982) Reticulospinal and vestibulospinal neurons in the young larva of a teleost fish, Brachidanio rerio. Prog. Brain Res. 57: $1-24$.

Kimmel, C. B., W. K. Metcalfe, and E. Schabtach (1985) T reticular interneurones: A class of serially repeating cells in the zebrafish hindbrain. J. Comp. Neurol. 233: 365-376.

Lamborghini, J. E. (1980) Rohon-Beard cells and other large neurons in Xenopus embryos originate during gastrulation. J. Comp. Neurol. 189: 323-333.

Letourneau, P. C. (1985) Axonal growth and guidance. In Molecular Bases of Neural Development, G. M. Edelman, W. E. Gall, and W. M. Cowan, eds., pp. 269-293, Wiley, New York.

McCaig, C. D. (1986) Dynamic aspects of amphibian neurite growth and the effects of an applied electric field. J. Physiol. (Lond.) 375: 5569

McCaig, C. D. (1987) Spinal neurite reabsorption and regrowth in vitro depend on the polarity of an applied electric field. Development 100: $31-41$.

Mendelson, B. (1986) Development of reticulospinal neurons of the Zebrafish. II. Early axonal outgrowth and cellbody position. J. Comp. Neurol. 251: 172-184.

Metcalfe, W. K., B. Mendelson, and C. B. Kimmel (1986) Segmental homologies among reticulospinal neurons in the hindbrain of the Zebrafish larva. J. Comp. Neurol. 251: 147-159.

Moody, S. A., and M. Jacobson (1983) Compartmental relationships between anuran primary spinal motoneurons and somitic muscle fibers that they first innervate. J. Neurosci. 3: 1670-1682.

Muntz, L. (1964) Neuromuscular foundations of behavior in embryonic and larval stage of the anuran, Xenopus laevis. $\mathrm{Ph}$. D. dissertation, Bristol University, Bristol.

Myers, P. Z., J. S. Eisen, and M. Westerfield (1986) Development of axonal outgrowth of identified motoneurons in the zebrafish. J. Neurosci. 6: $2278-2289$. 
Nieuwkoop, P. D., and J. Faber (1967) Normal Table of Xenopus laevis, Amsterdam, North-Holland.

Nordlander, R. (1987) Axonal growth cones in the developing amphibian spinal cord. J. Comp. Neurol. 263: 485-496.

Nordlander, R. H., and M. Singer (1982) Morphology and position of growth cones in the developing Xenopus spinal cord. Dev. Brain Res. 4: 181-193.

Nordlander, R., S. T. Bader, and T. Ryba (1985) Development of early brainstem projections to the tail spinal cord of Xenopus. J. Comp. Neurol. 231: 519-529.

Okado, N., and R. W. Oppenheim (1985) The onset and development of descending pathways to the spinal cord in the chick embryo. $\mathbf{J}$. Comp. Neurol. 232: 143-161.

Patel, N. B., and M.-M. Poo (1982) Orientation of neurite growth by extracellular electric fields. J. Neurosci. 2: 483-496.

Purves, D., and J. Lichtman (1985) Principles of Neural Development, Sinauer, Sunderland, MA.

Rakic, P. (1975) Local circuit neurons. Neurosci. Res. Prog. Bull. 13 . $291-446$.

Roberts, A., and S. T. Alford (1986) Descending projections and excitation during fictive swimming in Xenopus embryos: Ncuroanatomy and lesion experiments. J. Comp. Neurol. 250: 253-261.

Roberts, A., and J. D. W. Clarke (1982) The neuroanatomy of an amphibian embryo spinal cord. Phil. Trans. R. Soc. London [Biol.] 296: 195-212.

Roberts, A., and J. A. Kahn (1982) Intracellular recordings from spinal neurons during 'swimming' in paralysed amphibian embryos. Phil. Trans. R. Soc. London [Biol.] 296: 213-228.

Roberts, A., and B. Roberts (1983) Neural Origin of Rhythmic Movements, Cambridge Press, Cambridge.

Roberts, A., S. R. Soffe, J. D. W. Clarke, and N. Dale (1983) Initiation and control of swimming in amphibian embryos. Symp. Soc. Exp. Biol. 37: 261-284.

Roberts, A., S. R. Soffe, and N. Dale (1986) Spinal interneurons and swimming in frog embryos. In Neurobiology of Vertebrate Locomotion, S. Grillner, P. S. G. Stein, D. G. Stuart, H. Forssberg, and R. M. Herman, eds., pp. 279-306, Macmillan, London.

Rovainen, C. M. (1978) Müller cells, Mauthner cells, and other identified reticulospinal neurons in the lamprey. In Neurobiology of the Mauthner Cell, D. S. Faber and H. Korn, eds., pp. 245-269, Raven, New York.

Rovainen, C. M. (1979) Neurobiology of lampreys. Physiol. Rev. 59: 1007-1077.

Shapovalov, A. I. (1972) Evolution of neuronal systems of suprasegmental motor control. Neurophysiology 4: 346-359.

Shapovalov, A. I. (1975) Neuronal organization and synaptic mechanisms of supraspinal motor control in vertebrates. Rev. Physiol. Biochem. Pharmacol. 72: 1-54.
Soffe, S. R. (1985) Central coordination of swimming in lower vertebrates. Symp. Soc. Exp. Biol. 24: 141-162.

Soffe, S. R., and A. Roberts (1982a) Activity of myotomal motoneurons during fictive swimming in frogs. J. Neurophysiol. 48: 12741278.

Soffe, S. R., and A. Roberts (1982b) Tonic and phasic synaptic input to spinal cord motoneurons during fictive locomotion in frog embryos. J. Neurophysiol. 48: 1279-1288.

Soffe, S. R., J. D. W. Clarke, and A. Roberts (1984) Activity of commissural interneurons in the spinal cord of Xenopus embryos. J. Neurophysiol. 51: 1257-1267.

Stein, P. S. G. (1978) Motor systems, with special reference to the control of locomotion. Annu. Rev. Neurosci. 1: 61-81.

Takahashi, T., Y. Nakajima, K. Hirosawa, S. Nakajima, and K. Onodera (1987) Structure and physiology of developing neuromuscular synapses in culture. J. Neurosci. 7: 473-481.

ten Donkelaar, H. J. (1982) Organization of descending pathways to the spinal cord in amphibians and reptiles. In Descending Pathways to the Spinal Cord, H. G. J. M. Kuypers and G. F. Martin, eds., Prog. Brain Res. 57: 25-67, Elsevier, Amsterdam.

Tosney, K. W., and L. T. Landmesser (1985) Growth cone morphology and trajectory in the lumbosacral region of the chick embryo. J. Neurosci. 5: 2345-2358.

van Mier, P. (1986) The Development of the Motor System in the Clawed Toad, Xenopus laevis, Ph. D. dissertation, University of Nijmegen, Nijmegen.

van Mier, P. (1987) The development of early swimming in Xenopus embryos. In New Frontiers in Brain Research, N. Elsner and $\mathrm{O}$. Creutzfeld, eds., pp. 107, Thieme, Stuttgart.

van Mier, P. (1988) Reticulospinal neurons, locomotor control and the development of tailswimming in Xenopus. Acta Hung. Biol. (in press).

van Mier, P., and H. J. ten Donkelaar (1984) Early development of descending pathways from the brain stem to the spinal cord in Xenopus laevis. Anat. Embryol. 170: 295-306.

van Mier, P., and H. J. ten Donkelaar (1985) The ingrowth of supraspinal fibers into the spinal cord in Xenopus laevis as revealed by anterograde labeling. J. Neurosci. Letl. Suppl. 22: 343.

van Mier, P., R. van Rheden, and H. J. ten Donkelaar (1985) The development of the dendritic organization of primary and secondary motoneurons in the spinal cord of Xenopus laevis: An HRP study. Anta. Embryol. 172: 311-324.

van Mier, P., H. W. J. Joosten, R. van Rheden, and H. J. ten Donkelaar (1986) The development of serotonergic raphespinal projections in Xenopus laevis. Int. J. Dev. Neurosci. 4: 465-475.

van Mier, P., J. Armstrong, and A. Roberts (1989) The development of early swimming in Xenopus laevis embryos. Neuroscience (in press). 